\title{
DESIGN OF THREE PHASE INVERTER FED INDUCTION MOTOR DRIVE USING NEURAL NETWORK PREDICTIVE CONTROL
}

\author{
G.Jegadeeswari ${ }^{1}$, R. Arun Kumar ${ }^{2}$, F. Avila Priya ${ }^{3}$ \\ ${ }^{1}$ PG student, Department of Electrical and Electronics Engineering, Sri Manakula Vinayagar Engineering College, \\ Puducherry - 605107, India \\ ${ }^{2} P G$ student, Department of Electrical and Electronics Engineering, Sri Manakula Vinayagar Engineering College, \\ Puducherry - 605107, India \\ ${ }^{3} P G$ student, Department of Electrical and Electronics Engineering, Sri Manakula Vinayagar Engineering College, \\ Puducherry - 605107, India
}

\begin{abstract}
This paper presents a neural network predictive controller for three phase inverter fed induction machine speed control. Thus the three phase inverter fed induction motor drive has been simulated with and without step change using NNP controller. The performance comparisons of neural network predictive controller are achieved with the help of IAE (Integral absolute error) and ITAE (Integral time-weighted absolute error).
\end{abstract}

Keywords: NNP controller, Integral absolute error, and Integral time-weighted absolute error

\section{INTRODUCTION}

Nowadays, induction motor plays a vital role in industrial purposes. As compared to DC machine, it gives less cost and easy maintenance. However, the speed control of induction motor is more complex, which gives non-linear in nature. Therefore, speed variation can be achieved for this kind of machine by acting on the supply net frequency. There is no effective and simple way to vary the frequency of a supply until the present power electronics were developed.

On the other hand, in electric traction, the use of power is either DC or AC. Three phase DC/AC inverter is the only possible interface due to their flexible voltage and frequency variation. As mentioned above, a three phase DC/AC inverter used in traction is supplied by power either in AC or DC.

In the case of AC supply, it is directly connected to the three phase DC/AC inverter through step up/down transformer and an $\mathrm{AC} / \mathrm{DC}$ rectifier. The control problem in the induction motor is to design a controller ensuring a wide range of speed point for a three phase system and induction motor.

In the present work, a NNP controller is designed to control the motor speed by varying its reference value and to regulate the motor speed. It will be formally proved that NNP controller actually stabilizes the controlled system and does meet its tracking objectives with a good accuracy. ***

\section{METHODOLOGY}

The block diagram of the proposed work for neural network predictive controller is shown in fig 1 . The block diagram consists of DC supply as voltage source which is connected to a three-phase IGBT based inverter which is fed to an induction motor. A NNP controller is used for the control of triggering pulse of inverter switch. By varying the triggering pulse of the inverter a constant $(\mathrm{V} \backslash \mathrm{F})$ ratio is maintained for obtaining the speed of the induction motor.

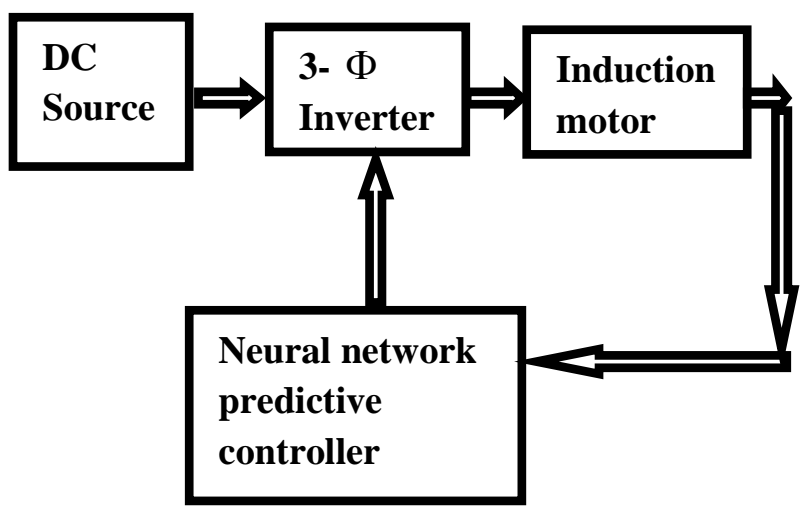

Fig 1: Overall Block diagram of proposed technique

The inverter used here is a three phase IGBT inverter which has the ability of decreasing and increasing the output voltage according to the requirement. The usage of inverter allocates 
the operation of induction machine even in low load conditions.

The intelligent controller used is Neural network predictive controller as shown in fig 1 which comprises the advantage of handling any type of self-tuning capabilities, information, self-learning, mimic human decision making process and self organizing etc which helps to control the induction motor more accurately when compare to other controllers.

\section{SPACE VECTOR MODULATION}

In the SVPWM algorithm, the d-axis and q-axis voltages are converted into three phase instantaneous reference voltages. The unreal switching time periods relative to the instantaneous values of the reference phase voltages and can be defined as

$$
V_{\alpha}+j V_{\beta}=\frac{2}{3}\left(V_{a}+e^{\frac{j 2 \pi}{3}} V_{b}+e^{\frac{-j 2 \pi}{3}} V_{c}\right)
$$

\section{Realization of Space Vector PWM}

- Step 1. Determine $\mathrm{V}_{\mathrm{d}}, \mathrm{V}_{\mathrm{q}}, \mathrm{V}_{\text {ref }}$, and angle $(\alpha)$

- Step 2. Determine time duration $T_{1}, T_{2}, T_{0}$

- Step 3. Determine the switching time of each transistor $\left(\mathrm{S}_{1}\right.$ to $\left.\mathrm{S}_{6}\right)$

Vref can be initiating with one zero vector and two active. For sector $1(0$ to $\pi / 3)$ : Vref can be located with V0, V1 and V2. Vref in terms of the duration time can be considered as:

$$
\begin{aligned}
& V_{\text {ref }} * T_{c}=V_{1} \frac{T_{1}}{T_{c}}+V_{2} \frac{T_{2}}{T_{c}}+V_{0} \frac{T_{0}}{T_{c}} \\
& V_{\text {ref }}=V_{1} T_{1}+V_{2} T_{2}+V_{0} T_{0}
\end{aligned}
$$

The total cycle is given by:

$$
T_{c}=T_{1}+T_{2}+T_{0}
$$

The position of Vref, $\mathrm{V}_{1}, \mathrm{~V}_{2}$ and $\mathrm{V}_{0}$ can be described with its magnitude and angle:

$$
\begin{gathered}
V_{\text {ref }}=V_{r e f} r^{j \theta} \\
V_{1}=\frac{2}{3} V_{D C} \\
V_{2}=\frac{2}{3} V_{D C} e^{\frac{j 2 \pi}{3}} \\
V_{o}=0 \\
T_{C}=\left(\begin{array}{c}
\cos \theta \\
\sin \theta
\end{array}\right) T_{1}\left(\frac{2}{3}\right) V_{D C}\left(\begin{array}{l}
1 \\
0
\end{array}\right)+T_{2}\left(\frac{2}{3}\right) V_{D C}\left(\begin{array}{c}
\cos \left(\frac{\pi}{3}\right) \\
\cos \left(\frac{\pi}{3}\right)
\end{array}\right)
\end{gathered}
$$

Dividing these in real and imaginary parts simplifies the calculation for each duration time:

\section{Real part:}

$$
T_{C} V_{\text {ref }} \cos \theta=T_{1}\left(\frac{2}{3}\right) V_{D C}+T_{2}\left(\frac{1}{3}\right) V_{D C}
$$

Imaginary part:

$$
T_{c} V_{\text {ref }} \sin \theta=T_{2}\left(\frac{1}{\sqrt{3}}\right) V_{D C}
$$

$\mathrm{T} 1$ and $\mathrm{T} 2$ are then given by:

$$
\begin{aligned}
& T_{1}=T_{c} \frac{\sqrt{3} V_{r e f}}{V_{D C}} \sin \left(\frac{\pi}{3}-\theta\right) \\
& =T_{c} \cdot a \cdot \sin \left(\frac{\pi}{3}-\theta\right) \\
& T_{2}=T_{c} \frac{\sqrt{3} V_{r e f}}{V_{D C}} \sin (\theta) \\
& =a \cdot \sin (\theta) \quad 0<\theta<\frac{\pi}{3}
\end{aligned}
$$

\section{CONTROLLER DESIGN}

\subsection{Neural Network Predictive Controller}

This predictive controller uses a neural network for a nonlinear model to predict the system future performance. The NNP controller calculates the controlled inputs that will optimize the system performance beyond a particular future time horizon. The early step in the predictive control is to estimate the neural network system model. Second step is the system model is used by the predictive controller to predict the future performance of the given system. The NNP controller uses the previous input and output to predict the future values of the system. The outlook of the neural network system model is given in the fig 2 .

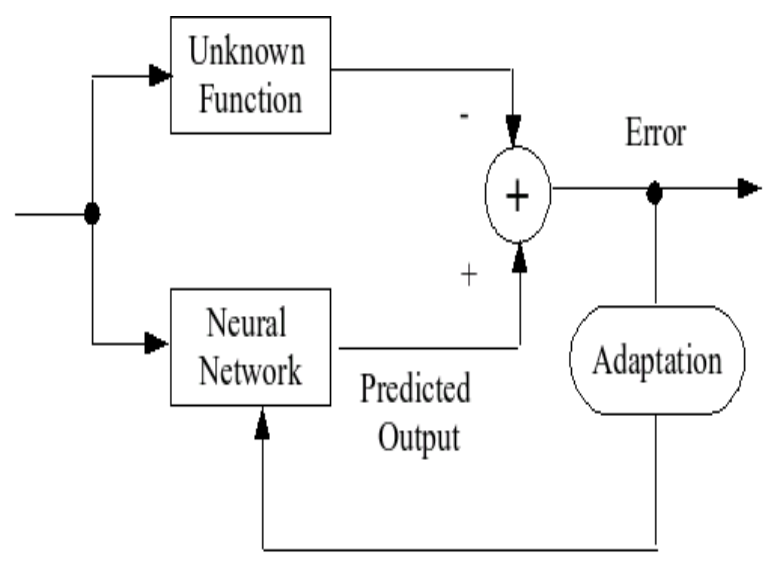

Fig: 2 Structure of NNP controller 
The aim approach which is used by the NNP control is to calculate the future response of the system and to eliminate the price utility based on the error between the predicted response of the system and the reference path. The price utility, which may be dissimilar from case to case, in order to get the best control input which is given to the non-linear system.

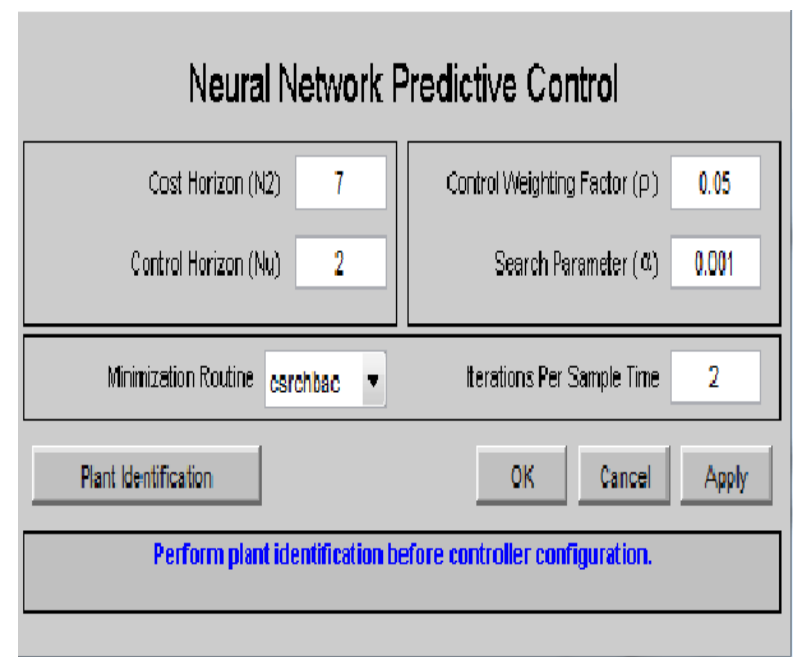

Fig: 3 neural network predictive control

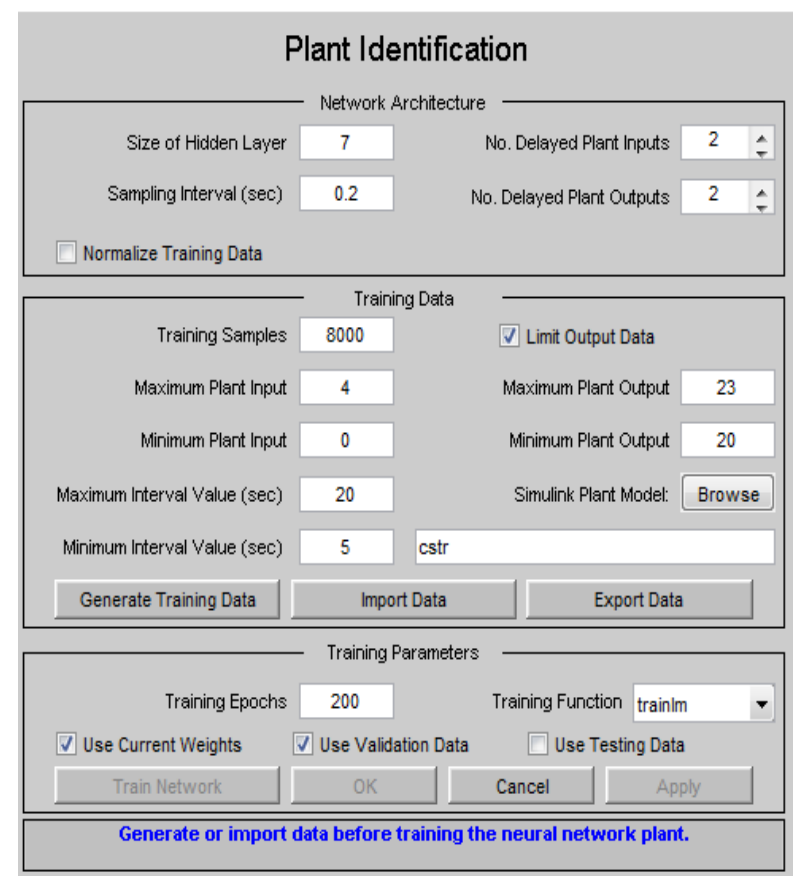

Fig:4 Plant identification for neural network predictive controller

With the large amount of data, neural network are used for training. The way of training the network is much easier than any other system. The other parameters are determined from actual system necessities. The main significant is to train the network and control the speed of the motor. The various specification need for system model is shown in fig 5 .

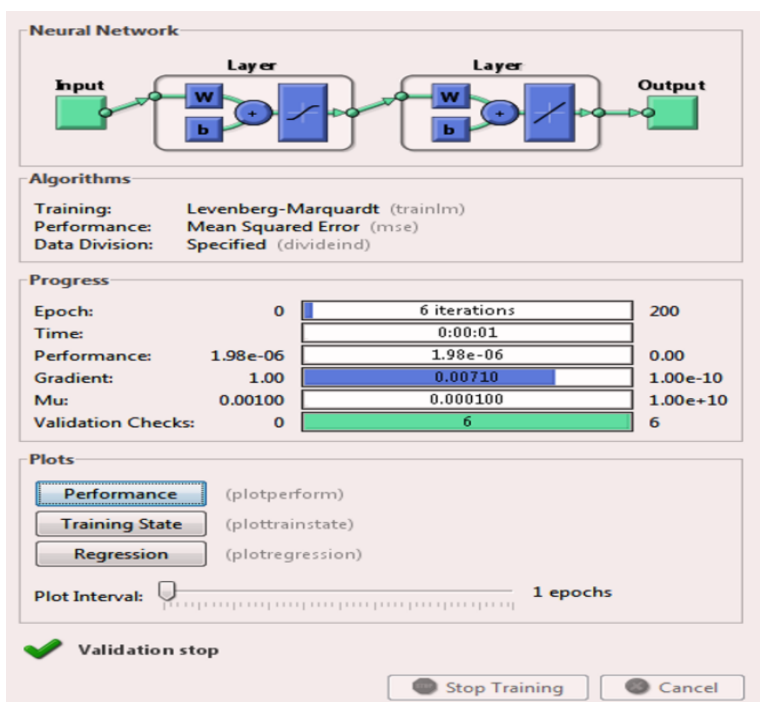

Fig:5 Plant identification

\section{RESULTS AND DISCUSSION}

The Matlab/Simulation results are shown in the following figures 6-9. Simulation is performed for the proposed circuit with MATLAB/SIMULINK version R2010a.

The response of induction motor with NNP controller is shown in the figures 8 and 9. The output voltage of three phase inverter $\mathrm{Va}, \mathrm{Vb}, \mathrm{Vc}$ which is shown in fig 6 gives the maximum output voltage of $520 \mathrm{~V}$. The switching pattern of SVPWM for inverter fed induction motor drive is shown in fig: 7

The reference value speed is considered as $1000 \mathrm{rpm}$ for Simulation results which are obtained under different operating conditions. The results obtained with NNP controlled drive is given in Figures 8 and 9. The performance of the drive during Step change in speed and load torque with NNP controller (load torque of $11 \mathrm{~N}-\mathrm{m}$ is applied at $0.5 \mathrm{sec}$ and removed at $1.5 \mathrm{sec}$ ) is shown Figure 8 . The steady state phase response is shown in Figure 9. It is observed that the ripple content in the current wave forms are less, the torque ripple reduced with NNP controller. 


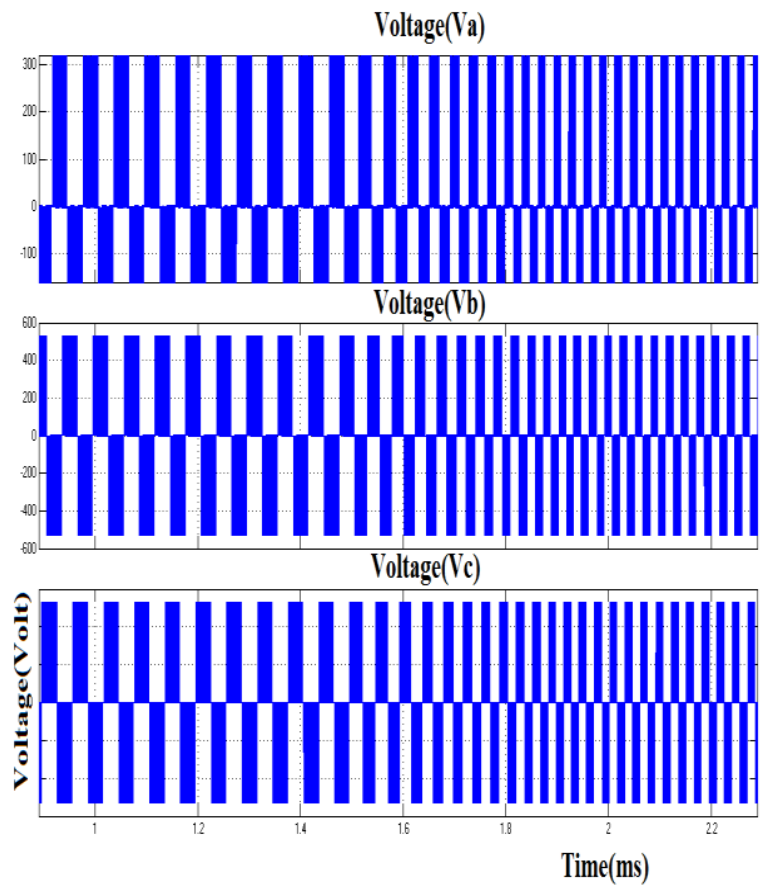

Fig: 6 Inverter output voltages

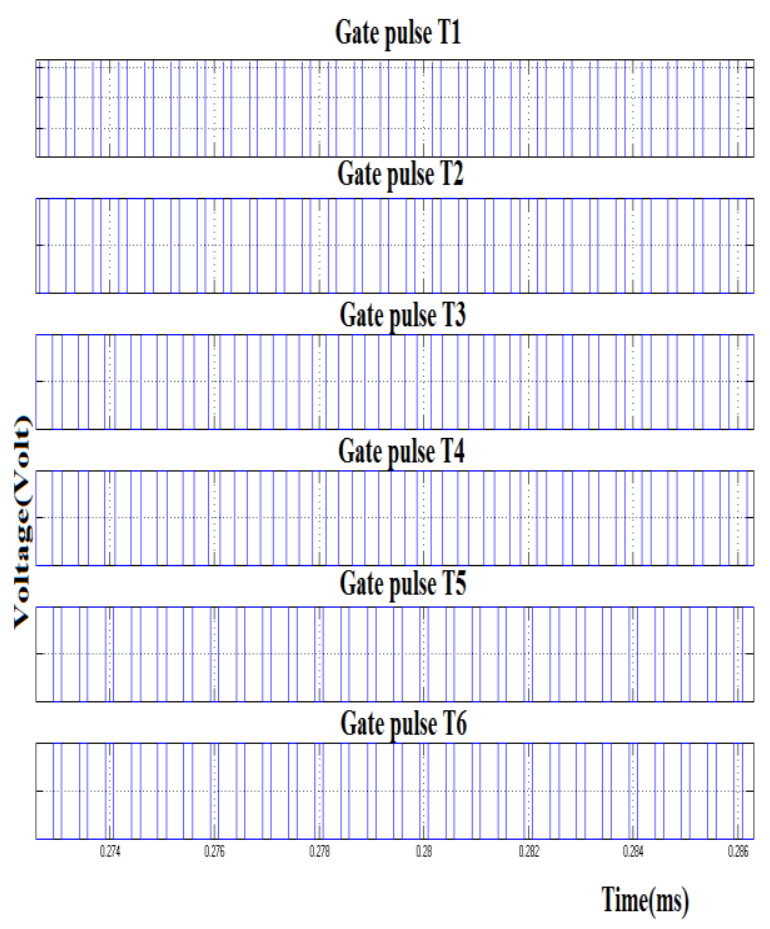

Fig: 7 switching pattern of SVPWM for inverter fed induction motor drive

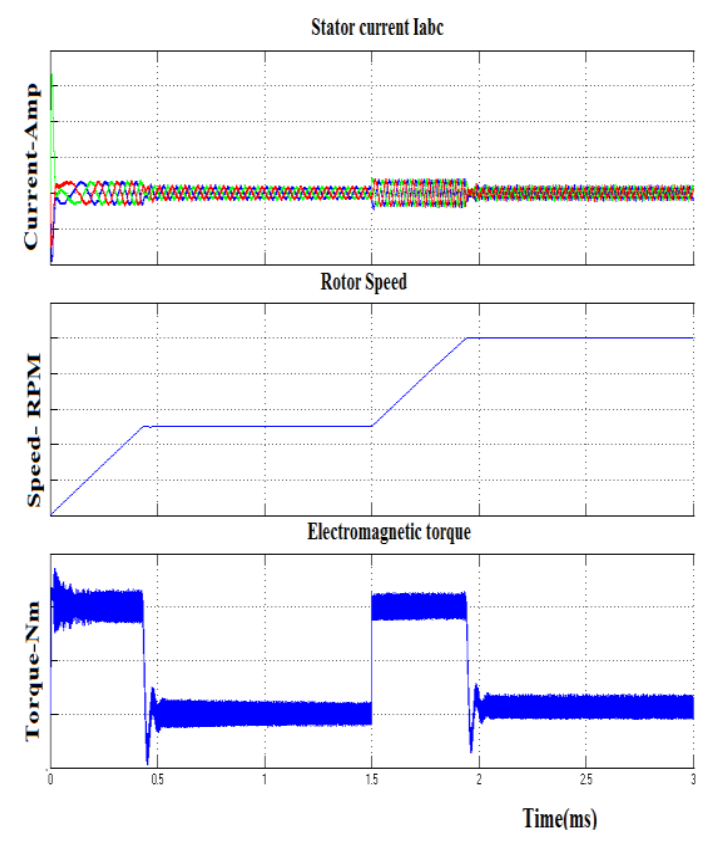

Fig: 8 Performance of induction motor without step change in load torque and speed With NNP controller
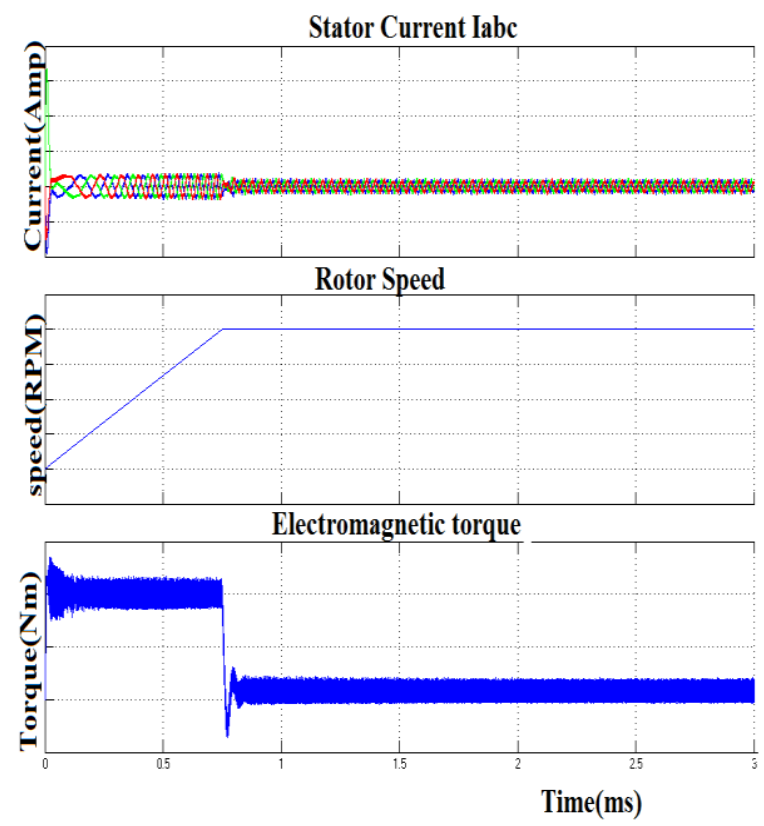

Fig: 9 Performance of induction motor with step change in load torque and speed With NNP controller 


\subsection{Performance Comparison Neural Network}

\section{Predictive Controller}

The performance comparison of Neural network predictive controller is achieved with the help of IAE (Integral absolute error) and ITAE (Integral time-weighted absolute error). The IAE and ITAE values of $\mathrm{NN}$ predictive controller for induction motor drive are shown in below table. The performance comparison is shown in table 1 .

Table: 1 performance comparison of NNP controller

\begin{tabular}{|l|l|l|}
\hline Controller & IAE & ITAE \\
\hline $\begin{array}{l}\text { Neural network } \\
\text { predictive } \\
\text { controller }\end{array}$ & 41.02 & 47.28 \\
\hline
\end{tabular}

\section{CONCLUSIONS}

This paper presents speed control of induction motor using Neural network predictive controller. In large perspective the overall performance of a drive under different operating conditions is improved with neural network predictive controller. The performance comparisons of Neural network predictive controller are achieved with the help of IAE (Integral absolute error) and ITAE (Integral time-weighted absolute error).

It has been formally established that the controllers actually meets the performance comparisons which is shown in table 1 and it has been designed to achieve, satisfactory rotor speed reference tracking over a wide range of speed reference variation. These results have been confirmed by a simulation study.

\section{APPENDIX}

\begin{tabular}{|l|l|}
\hline Parameters & Rated values \\
\hline Power & $50 \mathrm{hp}$ \\
\hline Voltage & $460 \mathrm{~V}$ \\
\hline Frequency & $60 \mathrm{~Hz}$ \\
\hline Stator/rotor resistances & $0.087 / 0.228 \Omega$ \\
\hline Stator/rotor inductances & $0.8 \mathrm{e}-3 \mathrm{H}$ \\
\hline Mutual inductance & $34.7 \mathrm{e}-3 \mathrm{H}$ \\
\hline Pole pairs & 2 \\
\hline Inertia & $\mathrm{J}$ \\
\hline
\end{tabular}

\section{REFERENCES}

[1]. A. El Fadili, F. Giri, A. El Magri, R. Lajouad, F.Z. Chaoui,. 2012 Towards a global control strategy for induction motor: Speed regulation, flux optimization and power factor correction... GREYC Lab., University of Caen, Caen, France
[2]. B.K. Bose. 1986. Power electronics and ac drives. Prentice hall Inc., Englewood Cliffs,

[3]. Pradeep B Jyoti, J.Amarnath, and D.Subbarayudu, Volume 4, Issue 3, May - June (2013), pp. 121-127, Application of Neuro-Fuzzy Controller In Torque Ripple Minimization Of Vector Controlled Vsi Induction Motor Drive.

[4]. A. El Fadili, F. Giri, A. El Magri, L. Dugard, H. Ouadi.2011 American Control Conference on O'Farrell Street, San Francisco, CA, USA June 29 - July 01, 2011, Induction Motor Control in Presence of Magnetic Saturation: Speed Regulation and Power Factor Correction

[5]. Lingji Chen*, Kumpati S. Narendra, Automatica 37 (2001) 1245 \}1255, Nonlinear adaptive control using neural networks and multiple models

[6]. Jasinski M, Cichowlas M, Kazmierkowski MP. Direct control for AC/DC/AC converter-fed induction motor with active filtering function. Int $\mathrm{J}$ Computer Math Electrical Electronic Eng 2006; 25:235-42.

[7]. Mohammad. Abdul Mannan, Toshiaki Murata, Junji Tamura,Takeshi Tsuchiya, "Indirect Field oriented control for high performance induction motor drives using space vector modulation with consideration of core loss", in proc. IEEE 34th Annual conf. power electronics, pp.1449-1454 ,2003.

[8]. C.Attainese, V.Nardi, and G.Tomasso, "Space vector modulation algorithm for power losses and THD reduction in VSI based drives," Electrical power components and systems, vol.35, pp.1271-1283, 2007.

[9]. B.Karthikeyan1 \& D.Sri Vidhya2, International Journal of Communications and Engineering Volume 05- No.5, Issue: 02 March2012, Performance Analysis Of Neuro-Fuzzy Based Speed Control Of Three Phase Induction Motor.

[10]. Ashok Kusagur,Dr. S. F. Kodad, Dr. B V. Sankar Ram, Modeling, Design \& Simulation of an Adaptive Neuro-Fuzzy Inference System (ANFIS) for Speed Control of Induction Motor, International Journal of Computer Applications (0975 - 8887)Volume 6- No.12, September 2010 